\title{
Technical setup and naming conventions
}

In order to facilitate fluent reading, some basic layouts are used avoiding text fragmentation and allowing the integration of code snippets to the red thread of each chapter.

\section{Program code}

All snippets are shortened so that just the core and the working principle are carved out. All listings have this form:

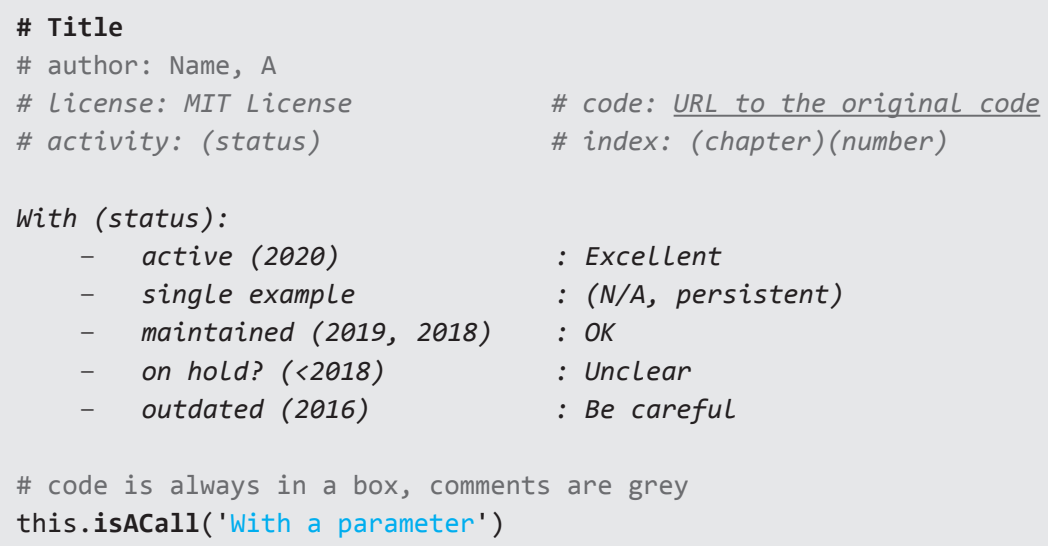

\section{Citations}

Bold text as well as text in blue + italic are citations and indicate intellectual property from other authors. There is always a reference at the end of each chapter.

\section{Legal questions}

All listings and citations in the book are based on license types that allow commercial use. Even the use of CC-BY-SA was avoided as the "SA/build upon material" is unclear from the perspective of a printed book. Only Wikipedia has enriched the SA license with a clear statement:

If you want to use Wikipedia's text materials in your own books/articles/web sites or other publications, you can generally do so, but you must comply with one of the licenses that Wikipedia's text is licensed under. If you make modifications or additions to the page 
you re-use, you must license them under the Creative Commons Attribution-Share-Alike License 3.0 or later. ${ }^{1}$

Even if not necessary, I give references to the creator and author - (please: avoid fantasy names in GitHub!). Some authors added license terms after request, thank you!

There are four related groups of licenses: Apache, MIT and BSD, CommonCreative, and GPL. All citations and code listings in this book have one of these types:

\begin{tabular}{|c|c|c|c|c|c|c|c|c|}
\hline License & Author & Version & Date & Link & $\begin{array}{l}\text { Commercial } \\
\text { use }\end{array}$ & Modify & $\begin{array}{l}\text { Patent } \\
\text { grant }\end{array}$ & TM grant \\
\hline $\begin{array}{l}\text { Apache } \\
\text { License }\end{array}$ & $\begin{array}{l}\text { Apache } \\
\text { Software } \\
\text { Foundation }\end{array}$ & 2 & 2004 & OK & OK & OK & Yes & No \\
\hline BSD License & $\begin{array}{l}\text { University of } \\
\text { California }\end{array}$ & 3.0 & & OK & OK & OK & (Part.) & (Part.) \\
\hline $\begin{array}{l}\text { BSD } \\
\text { License }\end{array}$ & $\begin{array}{l}\text { University of } \\
\text { California }\end{array}$ & $\begin{array}{l}\text { 2-Clause } \\
\text { "Simplified" }\end{array}$ & & & & & & \\
\hline MIT license & MIT & & 1988 & OK & OK & OK & (Part.) & (Part.) \\
\hline CC BY SA & $\begin{array}{l}\text { Creative } \\
\text { Commons }\end{array}$ & 4 & & OK & OK & $\begin{array}{l}\text { (Part.) } \\
\text { Share } \\
\text { alike* }^{\star}\end{array}$ & & \\
\hline $\begin{array}{l}\text { CC BY } \\
\text { (without } \\
\text { SA part) }\end{array}$ & $\begin{array}{l}\text { Creative } \\
\text { Commons }\end{array}$ & 4 & 2002 & OK & OK & OK & No & \\
\hline $\mathrm{CCO}$ & $\begin{array}{l}\text { Creative } \\
\text { Commons }\end{array}$ & & & OK & OK & OK & OK & OK \\
\hline $\begin{array}{l}\text { GNU LGPL } \\
\text { (not GPL) }\end{array}$ & $\begin{array}{l}\text { GNU Lesser } \\
\text { General } \\
\text { Public License }\end{array}$ & 3.0 & 2007 & OK & OK & $\mathrm{OK}$ & & \\
\hline Copyleft & \multicolumn{8}{|c|}{ Like GPL or CC-BY-SA } \\
\hline The Unlicense & \multicolumn{8}{|l|}{ Like CCO } \\
\hline
\end{tabular}

${ }^{\star}$ Remix, transform, or build upon the material (with change indication).

\section{Liability}

All information and program listings are for informational use only. There is no product liability. 


\section{Technical setup: Windows, Linux, or cloud}

A good platform for working is Anaconda with Python 3. Windows ${ }^{\mathrm{TM}}$ or Linux are equivalent, and Apple ${ }^{\mathrm{TM}}$ is not tested. On Windows, you can install a Linux subsystem and Ubuntu as an App. ${ }^{2}$

Sometimes there are citations of unported Python 2 code. Using \$2to3 - $n-w$ --add-suffix=3 example.py, can perform an semi-automatic transformation of ${ }^{3}$ the code but mostly some minor tweaks in function call, syntax, and error handling may remain manual.

\section{Working in the cloud/AWS}

A cloud-centric solution is based on an instance on Amazon with C9 (e.g., if you use Chromebooks like the author). As a cloud solution, it is not a local system; sometimes a few tricks are necessary, for example, using PyMol (C9 does not support XWindows).
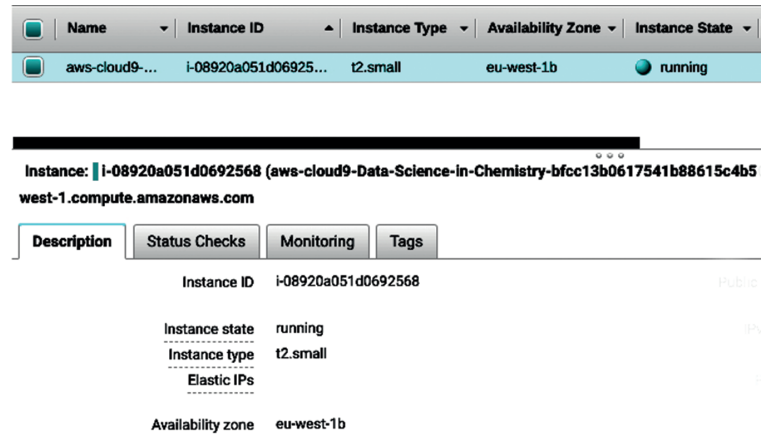

Figure Setup 1: Amazon C9 environment.

\section{Anaconda as a coding environment for the book}

Conda already has fully open package management and is on a steady trend toward fully open packages; see installation and handling in Chapter 11. Of course, other environments like Google Colab or IBM Watson Studio can be used, but there are limitations in environment installation and file handling. 


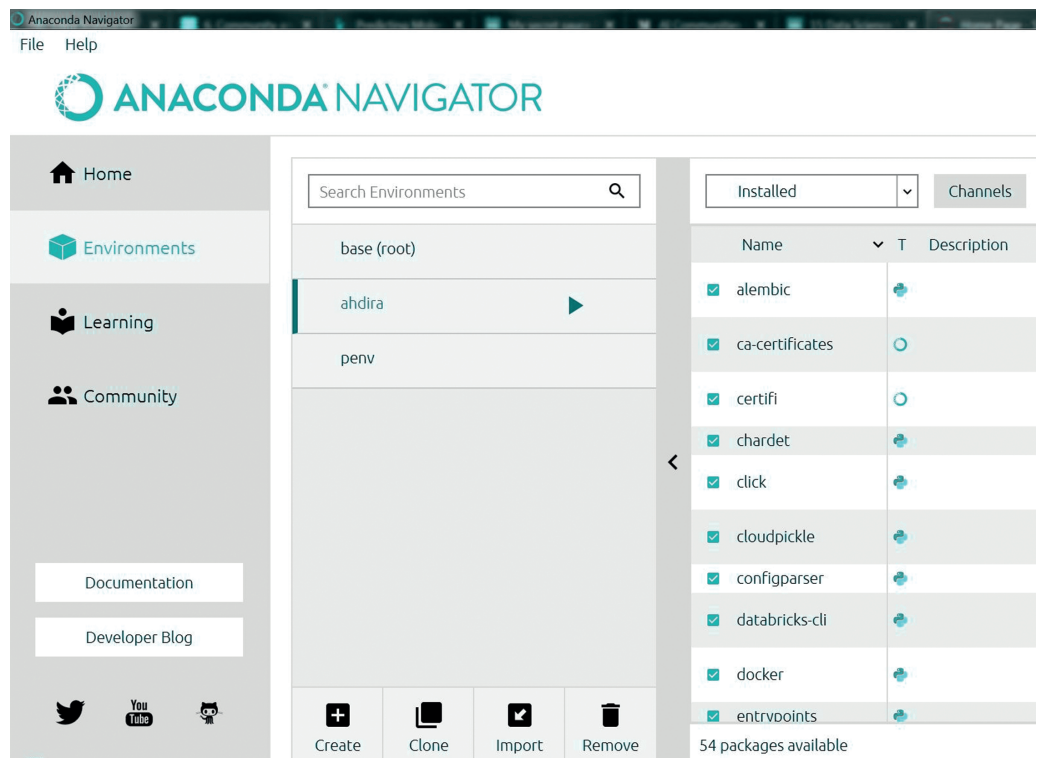

Figure Setup 2: Anaconda administration with environment and package management.

\section{References}

1. Reusing Wikipedia content (Wikipedia) https://en.wikipedia.org/wiki/Wikipedia:Reusing_ Wikipedia_content.

2. Install Windows Subsystem for Linux (WSL) on Windows 10 (Microsoft) https://docs.microsoft. com/en-us/windows/wsl/install-win10.

3. Python Software Foundation. Porting Python 2 Code to Python 3 https://docs.python.org/3/ howto/pyporting.html. 